\title{
Leaf Expansion and Transpiration Response to Soil Drying and Recovery among Cowpea Genotypes
}

\author{
Anju Manandhar, Thomas R. Sinclair, ${ }^{\star}$ Thomas W. Rufty, and Michel E. Ghanem
}

\begin{abstract}
Sensitivity of leaf expansion to water-deficit conditions could have a major influence on $\mathrm{C}$ assimilation rate and water loss rate under developing drought conditions. While cowpea (Vigna unguiculata L.) is commonly grown in more arid regions, there is no information on the sensitivity of its leaf expansion with drying soil. Three experiments were undertaken in controlled environments to document leaf expansion during increasing soil drying (11-13 d). Eight cultivars of cowpea were studied. It was found that the initiation of the decrease in leaf expansion occurred earlier in the soil drying cycle than the decrease in transpiration rate in all genotypes. Also, the soil water content at which leaf expansion completely stopped was slightly greater than the termination of transpiration. Therefore, both measures of leaf expansion sensitivity to soil water showed greater sensitivity to soil drying than plant gas exchange as measured by transpiration rate. Genotypic differences were observed among the genotypes in their sensitivity to soil drying. In one experiment, the severely stressed plants were rewatered and recovery in leaf expansion rate occurred very rapidly. Leaf expansion rates of all genotypes following rewatering returned to the rates of the well-watered plants within $\sim 1 \mathrm{~d}$.
\end{abstract}

A. Manandhar, T.R. Sinclair, T.W. Rufty, Crop and Soil Sciences Dep., North Carolina State Univ., Raleigh, NC 27695-7620; M. Ghanem, International Center for Agricultural Research in the Dry Areas (ICARDA), Rabat, Morocco. Received 2 Sept. 2016. Accepted 27 Feb. 2017. ${ }^{\star}$ Corresponding author (trsincla@ncsu.edu). Assigned to Associate Editor Ignacio Ciampitti.

Abbreviations: TSW, fraction of transpirable soil water; NLER, normalized leaf expansion ratio; NRT, normalized transpiration ratio; VPD, vapor pressure deficit.

Cowpea is an important grain legume crop used for food and stover grown in semiarid regions of the tropics and subtropics (Lim, 2012). Hence, it is often grown under drought-stress conditions that can result in yield losses. Minimizing these yield losses may be possible by developing plants that have a conservative pattern of water use through the growing season so that there is adequate water to sustain physiological activity through the critical period of seed fill. Therefore, one approach is to decrease water use early in the growing season in favor of use later in the season. One option to achieve this shift in water use is slow development of canopy leaf area since a large surface area is the source of transpirational water loss.

Leaf-area development has been identified as one of the most sensitive plant processes to water-deficit conditions (Boyer, 1968). Leaf-area expansion of soybean [Glycine max (L.) Merr.] (Sinclair and Ludlow, 1986) and of cowpea and black gram [Vigna mungo (L.) Hepper] (Sinclair et al., 1987) was reported as a function of the fraction of transpirable soil water (FTSW) remaining in drying soil. The FTSW at which leaf expansion was initially decreased to $98 \%$ of the well-watered plants was 0.28 for soybean, 0.35 for cowpea, and 0.40 for black gram. With further soil drying, zero leaf expansion was reached before transpiration soil water was exhausted with FTSW values of 0.05 for soybean and 0.02 for cowpea and black

Published in Crop Sci. 57:2109-2116 (2017).

doi: 10.2135/cropsci2016.09.0794

(C) Crop Science Society of America 5585 Guilford Rd., Madison, WI 53711 USA All rights reserved. 
gram. Serraj et al. (1999) measured leaf-area development for the soybean cultivar Braxton and found the decrease to $98 \%$ of the well-watered plants occurred at FTSW = 0.40 . Similar studies on the effects of drought stress on leaf expansion in field pea (Pisum sativum L.) cultivar Frilene (Lecoeur and Sinclair, 1996) showed the 98\% level occurred at FTSW $=0.53$. In a study of two chickpea (Cicer arietinum L.) cultivars, Soltani et al. (2000) found from a two-segment linear regression that the threshold for decline in leaf area expansion occurred at FTSW $=0.48$, and that the zero leaf expansion was reached at FTSW $=0.03$.

There are, however, few studies exploring leaf-area development in cowpea under soil drying. Only one genotype of cowpea was tested by Sinclair et al. (1987) and the nonlinear model used did not give an FTSW threshold for the initiation of a linear decrease in leaf expansion. Also, there are results from only the single cowpea genotype on the point of cessation of leaf expansion with soil drying. Not surprisingly, there is also no information on the recovery of cowpea leaf expansion when plants are rehydrated after drought-stress conditions. In regions with intermittent drought, the ability of crops to recover from drought stress could have a major affect the eventual crop productivity.

This research was intended to address this lack of information on cowpea leaf-area development by focusing on the sensitivity of the decline and cessation of leaf expansion with soil drying. Hence, the primary objective of this research was to detect the sensitivity of leaf expansion and cessation as compared with transpiration under developing drought. Two secondary objectives were studied to get preliminary information on (i) whether tolerance or sensitivity during soil drying gives genotypes any advantage in recovery from drought stress after rewatering and (ii) possible genotypic differences by studying the drought and recovery responses of eight genotypes included in this study.

\section{MATERIALS AND METHODS}

Eight cowpea genotypes (Bambey-21, IT82E-18, IT89KD-288, IT84S-2049, Mouride, UC-CB27, Suvita2, and IT93KD-5031) were selected for this study of leaf expansion from the 10 lines studied by Sinclair et al. (2015) for transpiration response to soil drying in a greenhouse experiment. Because of space limitations, only six of the eight genotypes were subsequently tested in two growth-chamber experiments (Bambey-21, IT82E-18, IT89KD-288, IT84S-2049, Mouride and Suvita2).

\section{Experimental Conditions}

The greenhouse experiment was done at Raleigh, NC, $\left(46^{\circ} 35^{\prime}\right.$ $\mathrm{N}, 39^{\circ} 78^{\prime} \mathrm{W}$ ) in May and June 2014 with temperature regulated for cooling at $28^{\circ} \mathrm{C}$. Actual temperature and relative humidity in the greenhouse was measured every 5 min using data loggers (Lascar Electronics). Vapor pressure deficit of the air was calculated from the temperature and humidity data. Incident photosynthetically active radiation to the greenhouse was obtained from the nearby Lake Wheeler Road Meteorological Station (State Climate Office of North Carolina). Supplemental metal halide lamps were used from 6:00 to 10:00 PM EST to extend the light period to $\sim 16 \mathrm{~h}$ to help maintain the plants in a vegetative state during the experiment.

The growth chamber experiments were done in a walkin, controlled-environment chamber in the North Carolina State University Phytotron facility. The day and night temperatures were set to be 30 and $24^{\circ} \mathrm{C}$, respectively. Temperature and relative humidity were also measured in the growth chambers every 5 min using data loggers (Lascar Electronics), and these data were used to calculate vapor pressure deficit. Photosynthetically active radiation in the growth chambers from a combination of fluorescent and incandescent lamps (Saravitz et al., 2009) was measured once a month. The first growth chamber experiment had a daylength of $16 \mathrm{~h}$. The second growth chamber experiment had a daylength of $12 \mathrm{~h}$ with a 3-h darkperiod interruption with light from incandescent lamps.

For all experiments, the plants were grown in $20-\mathrm{cm}$ diam. plastic pots with a volume of $4 \mathrm{~L}$ filled with the same loamy sand soil (69\% sand, 18\% silt, and 13\% clay). Eight pots were used for each genotype in the greenhouse and first growth chamber experiments. Once the dry-down test began, the eight pots were divided between three for the well-watered treatment and five for the drying treatment. In the second growth chamber experiment, 13 pots were used for each genotype with three ultimately used as the well-watered treatment and 10 for the drying treatment.

Before sowing, the seeds were inoculated with Bradyrhizobium japonicum (N-Dure, INTX Microbials). The greenhouse experiment was sown on 9 May 2014 and the beginning of the dry-down experiment was on 2 June 2014. Plants were thinned to one plant per pot after the first trifoliolate leaf emerged. Any occasional flower that emerged was removed to maintain the plants in a vegetative state.

Initially, all plants were grown under well-watered conditions by watering the pots daily with deionized water (100-200 g). During the greenhouse experiment, a nutrient solution $(\mathrm{N}$, $17.9 \mathrm{mM}$; P, $4.0 \mathrm{mM}$; and $\mathrm{K}, 9.0 \mathrm{mM}$ ) was prepared using MaxiGro (General Hydroponics) and applied to the plants once a week. For the growth chamber experiments, the nutrient solution $(\mathrm{N}$, $7.6 \mathrm{mM}$; P, $0.3 \mathrm{mM}$; L $2.8 \mathrm{mM}$; plus micronutrients) as prepared in the Phytotron facility was applied twice a week. Information pertaining to the composition of the nutrient solution can be found in the Phytotron Procedural Manual (Saravitz et al., 2009).

\section{Dry-Down Treatment}

When the plants reached V4 to V5 stage, the dry-down test was initiated. In the evening before treatments were imposed, all pots were watered until dripping. The pots were allowed to drip overnight to permit the soil to drain to pot capacity by the following morning. In the morning, the pots were enclosed in plastic bags, which were tied around the main plant stem to prevent soil water evaporation. Then the pots were weighed to obtain the pot initial weight.

During the following days of the experiment, all pots were weighed daily to calculate transpiration rate by difference in successive weights between days. For the greenhouse experiment and the first chamber experiment, the well-watered pots were rewatered daily to maintain a pot weight of $200 \mathrm{~g}$ below 
their initial weight. For the progressive drought treatment, the soil was allowed to dry by plant transpiration. However, to ensure development of drought over $\sim 2 \mathrm{wk}$, the stressed pots were watered on each day when their water loss was greater than $100 \mathrm{~g}$ so that the net daily water loss was no greater than $100 \mathrm{~g}$. A drought period of approximately 12 to $14 \mathrm{~d}$ was targeted because shorter dry-down periods often do not provide the intensity of data to allow discrimination among genotypes in plant response to soil drying.

Because of high vapor pressure deficit (VPD) during the first chamber experiment the dry-down period was shorter than desired ( $8 \mathrm{~d}$ ), so the protocol for the second chamber experiment was adjusted to lengthen the experiment. To decrease the transpiration rate, VPD of the growth chamber in this second experiment was maintained in the range of 1 to $2 \mathrm{kPa}$ by adding two humidifiers (Ultrasonic humidifier, Kaz Inc.) in the growth chamber. The criterion for rewatering the waterdeficit pots was also changed to achieve a slower rate of dry down. Instead of rewatering the stressed pots to maintain daily water loss to $100 \mathrm{~g}$ or less, in this second chamber experiment rewatering was done to keep daily water loss to $60 \mathrm{~g}$ or less. In this second experiment, the well-watered pots were watered daily to return pot weight to $150 \mathrm{~g}$ below their initial weight.

\section{Leaf Expansion}

Leaf expansion was tracked by measuring the length of each terminal leaflet on each plant every $24 \mathrm{~h}$ until the leaflet length was no longer increasing. Corresponding node numbers were also recorded. At the end of the experiment, the length of each terminal leaflet and its corresponding trifoliolate leaf area was measured (LI-3100C, Li-cor). A quadratic relationship between the terminal leaflet length and the area of the corresponding trifoliolate leaf was developed for each genotype. The relationship between terminal leaflet length and leaf area was used to find the daily leaf area of each plant. The daily leaf area results were used to calculate by difference the leaf total expansion per day for each plant during the experiment.

\section{Recovery}

Recovery of transpiration rate and leaf area expansion after severe drought stress was measured in the second chamber experiment. At the end of the drought-stress period for each stressed plant, when NTR $\leq 0.10$, that plant was rewatered so its pot weight was returned to $150 \mathrm{~g}$ below initial weight. Each day, the pots were weighed and water added for at least a $5-\mathrm{d}$ recovery period. Also, on each day during the recovery period, terminal leaflet lengths were measured to estimate leaf area increase.

\section{Data Analysis}

Transpiration rate was calculated for each pot from the change in pot weight between successive days. To obtain a transpiration ratio, daily transpiration of each stress plant was divided by the mean transpiration rate of the three well-watered plants within each genotype on the same day. This transpiration ratio helped to minimize daily variation as a result of differing environmental conditions. To reduce plant-to-plant variation, daily normalized transpiration ratio (NTR) was calculated for each stressed plant by dividing its daily transpiration ratio by its average transpiration ratio during the first $3 \mathrm{~d}$ of the experiment when the plant was not yet suffering drought. This procedure meant that the initial NTR of each stressed plant was centered on 1.0. The stressed pots were allowed to dry until daily NTR reached a value equal to or less than 0.10 .

The difference between the initial pot-capacity weight and the weight at the end of the drought-stress period (NTR $\leq$ 0.10) was used to calculate the total transpiration soil water of each pot. The FTSW in each pot on each day over the course of the dry down was calculated using the following equation.

$$
\begin{array}{r}
\text { FTSW }=(\text { daily wt. }- \text { final wt. }) / \\
\text { (initial wt. }- \text { final wt. })
\end{array}
$$

Normalized leaf expansion ratio (NLER) was calculated similar to NTR as described by Serraj et al. (1999). The calculated leaf area was used to find the total expansion per day for each plant during the experiment. The daily expansion ratio for each stress plant was calculated by using the average expansion observed for the three well-watered plants of the same genotype. Normalized leaf expansion ratio for each day for each stress plant was calculated by dividing the daily leaf expansion ratio by the average of expansion measured in the stress plant during the first $3 \mathrm{~d}$ of the experiment.

For each genotype, daily NTR and NLER of all plants of a genotype were combined, plotted against FTSW, and subjected to a two-segment linear regression (Prism 6 software, Graphpad Software Inc.). The output of this regression included threshold at which NTR and NLER started to decline with decreasing soil water content (i.e., FTSW). These regression results were also used to extrapolate the response of NTR and NLER to find the FTSW values at which NTR and NLER reached zero.

During the recovery period, the transpiration and leaf expansion of recovering plants were normalized against the transpiration and leaf expansion rates of the last $2 \mathrm{~d}$ of the recovery for each recovering plant. A two-segment linear regression using Prism was used to describe the changes in both NTR and NLER during the days of recovery.

\section{RESULTS}

\section{Environmental Conditions}

Differences in the environmental variables of temperature, VPD, and light were found among the experiments. Figure 1 shows the average daily daytime temperature and VPD during the course of the three experiments. The 5- $d$ average temperatures covering the period when FTSW thresholds were reached in the experiments were similar at 31.2, 29.0 , and $30.3^{\circ} \mathrm{C}$ for the greenhouse, first growth-chamber experiment, and second growth-chamber experiment, respectively. The 5-d average VPD for the greenhouse experiment during the period when FTSW thresholds were reached was $2.4 \mathrm{kPa}$. The first growth-chamber experiment had a 5-d average VPD of $2.1 \mathrm{kPa}$ and the second growthchamber experiment had a VPD average of $1.3 \mathrm{kPa}$. Based on the $95 \%$ confidence interval of the averages for each of the three experiments, there was significant difference in 
A. Vapor Pressure Deficit

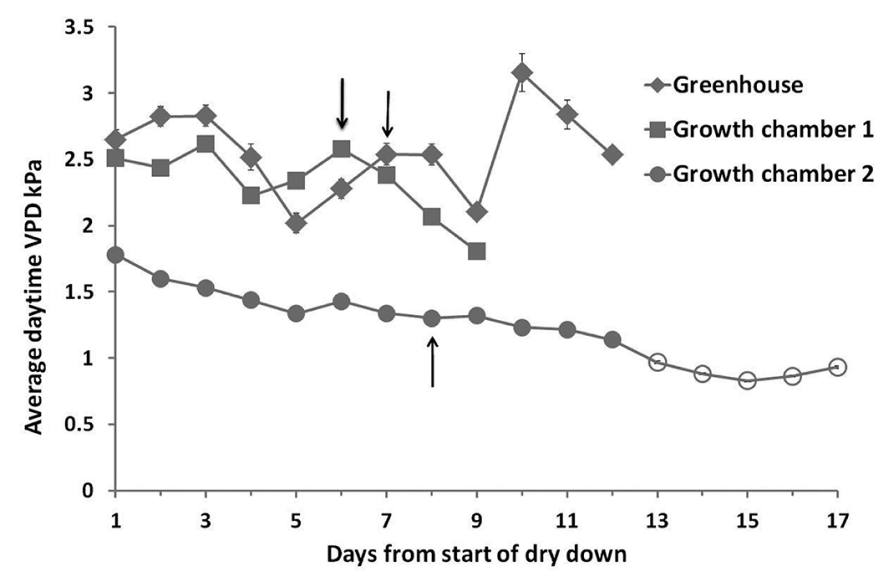

B. Temperature

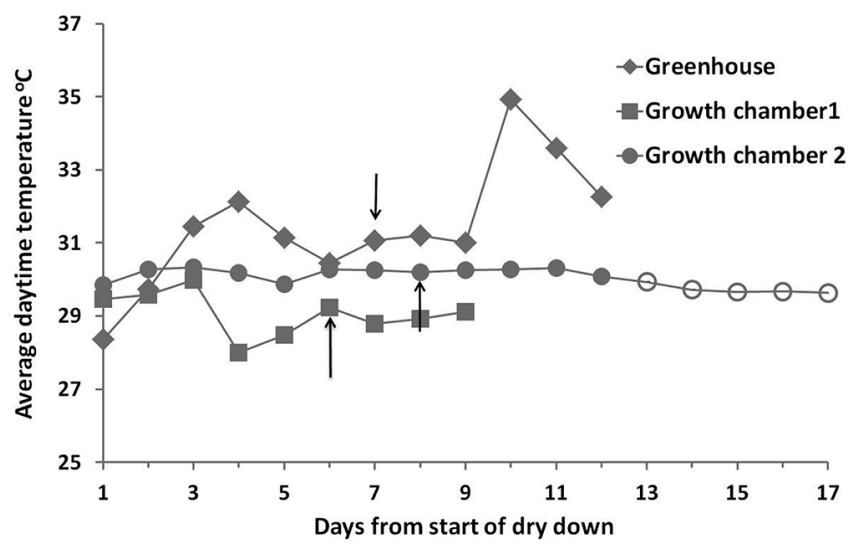

Fig. 1. Average daytime vapor pressure deficit (VPD) and temperature on each day during the dry-down experiments. Open circles represent the data during the period of recovery. Arrows designate average day the plants started reaching fraction transpirable soil water (FTSW) threshold for normalized transpiration ratio (NTR).

the VPD between the greenhouse and the second growthchamber experiments. The average photosynthetically active photon flux density in the greenhouse experiment ranged from 417 to $690 \mu$ mols $\mathrm{m}^{-2} \mathrm{~s}^{-1}$. The photon flux density for the first and second growth-chamber experiments ranged from 520 to $545 \mu$ mols m ${ }^{-2} \mathrm{~s}^{-1}$.

The criterion for daily watering of the drought-stressed pots was effective in extending the average duration of the dry-down period during the greenhouse experiment to 13 d. However, the VPD conditions and watering regime in the first growth chamber study resulted in a shortened drought period of $8 \mathrm{~d}$. Adjusting the chamber VPD and rewatering criterion resulted in extending the dry-down period to $11 \mathrm{~d}$ during the second growth-chamber experiment.

\section{Leaf Expansion}

For most genotypes, the plots of both NLER (and NTR) vs. FTSW were well represented by the linear, twosegmented model. As illustrated in Fig. 2 with genotype IT89KD-288 for both variables, the initial phase of soil drying was represented by a plateau followed by a linear decrease below a FTSW threshold. A higher threshold reflected a greater sensitivity to soil drying.

Table 1 summarizes the FTSW thresholds for decrease in leaf expansion (i.e., NLER). There was substantial variation among genotypes. In the greenhouse experiment, Bambey-21 had the NLER threshold at the lowest FTSW of 0.35. UC-CB27 had the threshold at the highest FTSW at 0.67 . In the first growth-chamber experiment, the FTSW threshold range was 0.26 to 0.37 for NLER with the lowest found for IT84S-2049 and the highest found for Suvita 2. In the second growth-chamber experiment, the FTSW thresholds for NLER were in the range of 0.28 to 0.41 FTSW, as obtained for IT82E-18 and Mouride, respectively.

Considering the 95\% confidence intervals for the NLER threshold, IT89KD-288 and Suvita 2 had high thresholds
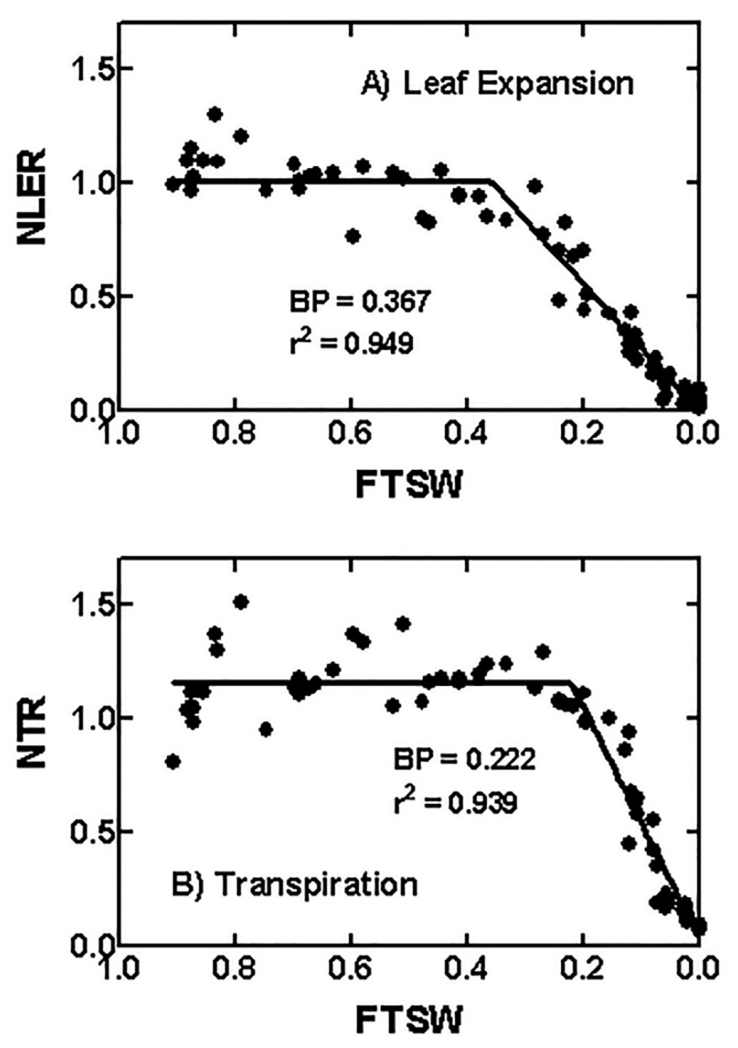

Fig. 2. Graph of normalized leaf area ratio (NLER) and normalized transpiration ratio (NTR) vs. fraction transpirable soil water (FTSW) during growth-chamber Exp. 1 for genotype IT89KD-288. The two-segmented regression was used to fit these data and the threshold for the decline (BP) is noted in the figures.

across the three experiments among the tested genotypes. However, no genotype consistently exhibited a low NLER threshold across all three experiments, indicating inconsistent drought tolerance in leaf expansion. Bambey 21 and Mouride showed low thresholds for NLER in the greenhouse and first chamber experiment, but this response was not confirmed in the second chamber experiment. 
Table 1. Fraction transpirable soil water (FTSW) threshold for initiation of decline in normalized leaf expansion ratio (NLER) as determined by the two-segment, linear-regression analysis. Those thresholds identified with different letters were significantly different between genotypes. Also, presented are the $95 \%$ confidence intervals (Cls) and $R^{2}$ from the regression analysis.

\begin{tabular}{|c|c|c|c|c|c|c|c|c|c|}
\hline \multirow[b]{2}{*}{ Genotype } & \multicolumn{3}{|c|}{ Greenhouse experiment } & \multicolumn{3}{|c|}{ Growth chamber Exp. 1} & \multicolumn{3}{|c|}{ Growth chamber Exp. 2} \\
\hline & Threshold & $\mathrm{Cl}$ & $R^{2}$ & Threshold & $\mathrm{Cl}$ & $R^{2}$ & Threshold & $\mathrm{Cl}$ & $R^{2}$ \\
\hline Bambey-21 & $0.351 \mathrm{a}$ & $0.259-0.443$ & 0.71 & $0.310 a b$ & $0.284-0.336$ & 0.96 & $0.372 b$ & $0.343-0.400$ & 0.92 \\
\hline IT93K-503-1 & $0.413 a$ & $0.346-0.481$ & 0.87 & - & - & - & - & - & - \\
\hline Mouride & $0.464 a b$ & $0.395-0.533$ & 0.87 & $0.276 a$ & $0.248-0.304$ & 0.92 & $0.408 b$ & $0.345-0.471$ & 0.75 \\
\hline IT82E-18 & $0.554 b c$ & $0.487-0.621$ & 0.91 & $0.342 b$ & $0.308-0.377$ & 0.93 & $0.284 a$ & $0.247-0.321$ & 0.87 \\
\hline IT84S-2049 & $0.589 \mathrm{bc}$ & $0.489-0.690$ & 0.80 & $0.259 a$ & $0.230-0.289$ & 0.92 & $0.341 a b$ & $0.315-0.348$ & 0.93 \\
\hline Suvita2 & $0.647 \mathrm{c}$ & $0.542-0.751$ & 0.83 & $0.368 \mathrm{~b}$ & $0.338-0.397$ & 0.95 & $0.363 b$ & $0.328-0.398$ & 0.90 \\
\hline IT89KD-288 & $0.657 \mathrm{c}$ & $0.562-0.752$ & 0.86 & $0.367 \mathrm{~b}$ & $0.334-0.399$ & 0.95 & $0.334 a b$ & $0.309-0.358$ & 0.93 \\
\hline U-CB27 & $0.674 \mathrm{c}$ & $0.567-0.782$ & 0.83 & - & - & - & - & - & - \\
\hline
\end{tabular}

Table 2. Fraction transpirable soil water (FTSW) threshold for initiation of decline in normalized transpiration ratio (NTR) as determined by the two-segment, linear-regression analysis. Those thresholds identified with different letters were significantly different between genotypes. Also, presented are the $95 \%$ confidence intervals (Cls) and $R^{2}$ from the regression analysis.

\begin{tabular}{|c|c|c|c|c|c|c|c|c|c|}
\hline \multirow[b]{2}{*}{ Genotype } & \multicolumn{3}{|c|}{ Greenhouse experiment } & \multicolumn{3}{|c|}{ Growth chamber Exp. 1} & \multicolumn{3}{|c|}{ Growth chamber Exp. 2} \\
\hline & Threshold & $\mathrm{Cl}$ & $R^{2}$ & Threshold & $\mathrm{Cl}$ & $R^{2}$ & Threshold & $\mathrm{Cl}$ & $R^{2}$ \\
\hline Bambey-21 & $0.308 a$ & $0.287-0.329$ & 0.98 & $0.254 a$ & $0.238-0.271$ & 0.97 & $0.202 a$ & $0.182-0.222$ & 0.89 \\
\hline IT93K-503-1 & $0.346 a b$ & $0.321-0.370$ & 0.97 & - & - & - & - & - & - \\
\hline Suvita2 & $0.393 \mathrm{bc}$ & $0.366-0.419$ & 0.97 & $0.240 a$ & $0.218-0.261$ & 0.96 & $0.329 c$ & $0.306-0.353$ & 0.94 \\
\hline IT82E-18 & $0.399 c$ & $0.377-0.421$ & 0.98 & $0.249 a$ & $0.230-0.268$ & 0.96 & $0.260 b$ & $0.233-0.286$ & 0.90 \\
\hline Mouride & $0.430 \mathrm{~cd}$ & $0.380-0.481$ & 0.93 & $0.249 a$ & $0.231-0.266$ & 0.97 & $0.277 \mathrm{bc}$ & $0.244-0.309$ & 0.85 \\
\hline IT89KD-288 & 0.493 de & $0.443-0.543$ & 0.94 & $0.222 a$ & $0.201-0.244$ & 0.94 & $0.289 \mathrm{bc}$ & $0.266-0.311$ & 0.92 \\
\hline IT84S-2049 & $0.521 \mathrm{de}$ & $0.470-0.573$ & 0.93 & $0.251 a$ & $0.233-0.269$ & 0.97 & $0.331 c$ & $0.303-0.359$ & 0.91 \\
\hline UC-CB27 & $0.578 \mathrm{e}$ & $0.496-0.660$ & 0.85 & - & - & - & - & - & - \\
\hline
\end{tabular}

The FTSW intercepts at the zero point of NLER was within a fairly narrow range for all genotypes in each experiment. For the greenhouse experiment, FTSW intercept ranged from 0.01 to 0.05 with an average of 0.01 . Because of the short duration of the first growth-chamber experiment, extrapolations of the results to zero FTSW were considered unreliable. The FTSW intercept in the growth-chamber experiment ranged from an FTSW of -0.02 to 0.03 with an average of 0.007 .

\section{Transpiration}

As a useful reference in examining leaf expansion, transpiration response to soil drying was calculated for each genotype. Table 2 presents the FTSW thresholds for decrease in NTR from all experiments. There was considerable difference in the range of the thresholds among genotypes across experiments. The FTSW threshold range in the greenhouse experiment was 0.31 to 0.58 . The first growth-chamber experiment, in which the duration of the dry-down was short, exhibited the smallest threshold range among genotypes of only 0.22 to 0.25 . This lack of discrimination among genotypes has been previously obtained when the dry-down period is short. The second growth-chamber experiment had a range in NTR threshold of 0.20 to 0.33 .

The extrapolated FTSW intercept at which NTR is zero had a range of -0.06 to -0.01 , with an average of -0.03 , in the greenhouse experiment. In the second growth-chamber experiment, the range of FTSW intercept was from -0.05 to -0.01 with an average of -0.03 .

Comparison of transpiration results among genotypes showed similar rankings in FTSW at threshold of decrease in NTR in the greenhouse experiment and second growth-chamber experiment. Only Suvita 2 showed differences in the ranking of threshold between the two experiments. In both experiments, Bambey-21 had the lowest NTR threshold of 0.31 and 0.20 in the greenhouse experiment and in the second growth-chamber experiment, respectively. IT84S-2049 had the highest FTSW threshold of 0.33 in the second growth-chamber experiment and one of the highest FTSW thresholds at 0.52 in the greenhouse experiment. The FTSW thresholds found in the first growth-chamber experiment, however, showed no significant differences among genotypes, presumably a result of the short duration in the imposition of drought.

\section{Comparison of Fraction Of Transpirable Soil Water Threshold and Intercepts between Normalized Leaf Expansion Ratio and Normalized Transpiration Ratio}

The FTSW thresholds for decrease in NLER occurred at higher FTSW than for NTR within genotypes for all experiments (Fig. 3). Comparison of the $95 \%$ confidence interval 


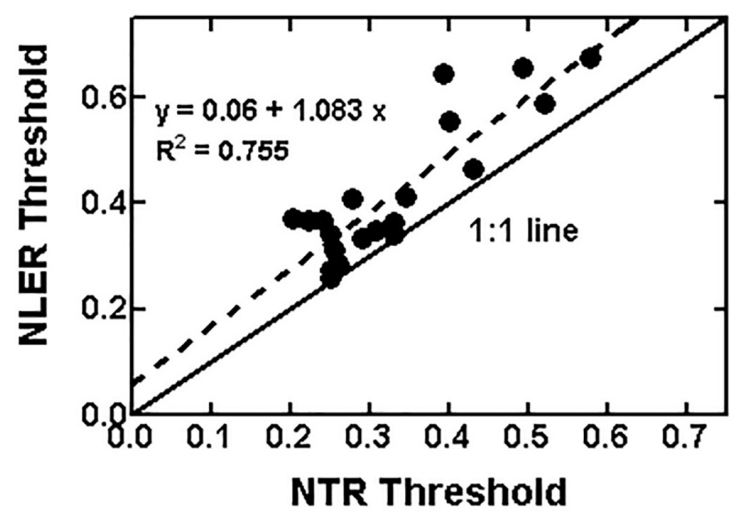

Fig. 3. Data for each genotype and experiment of fraction transpirable soil water (FTSW) threshold for initiation of decline of the normalized leaf expansion ratio (NLER) vs. FTSW threshold for initiation of decline of the normalized transpiration ratio (NTR).

between FTSW thresholds of NLER and NTR in the second growth-chamber experiment showed that the threshold point for NLER occurred at a significantly higher FTSW than NTR in Bambey 21 and Mouride. The regression for NLER vs. NTR for the combined data from all experiments showed that the FTSW thresholds for the initiation of the decrease of each were significantly related $(p<0.0001)$. For each experiment individually, the correlation between NLER and NTR was lower or nonsignificant likely because of fewer data within a narrow range of threshold values.

\section{Recovery}

Regressions of both NLER and NTR vs. days of recovery following watering of the stressed plants in the second growth-chamber experiment were also analyzed using the two-segment linear model (Fig. 4). The increase in NTR and NLER from values of $<0.10$ was rapid until plateau values were reached, which was defined to be the normalized value of 1.0 for the two variables. No differences in days to full recovery were seen among genotypes (Table 3). The days required for full recovery of NTR ranged from 2.0 to $2.3 \mathrm{~d}$. The recovery leaf expansion to NLER of 1.0 was calculated to have occurred in a range of 0.7 to $1.1 \mathrm{~d}$.

Since recovery occurred rapidly and no differences were seen in recovery among genotypes, it was not possible to explore correlations within genotypes in response to the dry-down phase in comparison to the recovery phase. Although it was clear that leaf expansion during the soil-drying phase was more sensitive than transpiration rate but recovered more quickly following rewatering.

\section{DISCUSSION}

Drought is the main limitation on crop yield including for cowpea. Since a key process that might be especially sensitive to water deficit is leaf expansion, the objective of this study was to determine the sensitivity of leaf expansion in cowpea genotypes to soil drying and compare
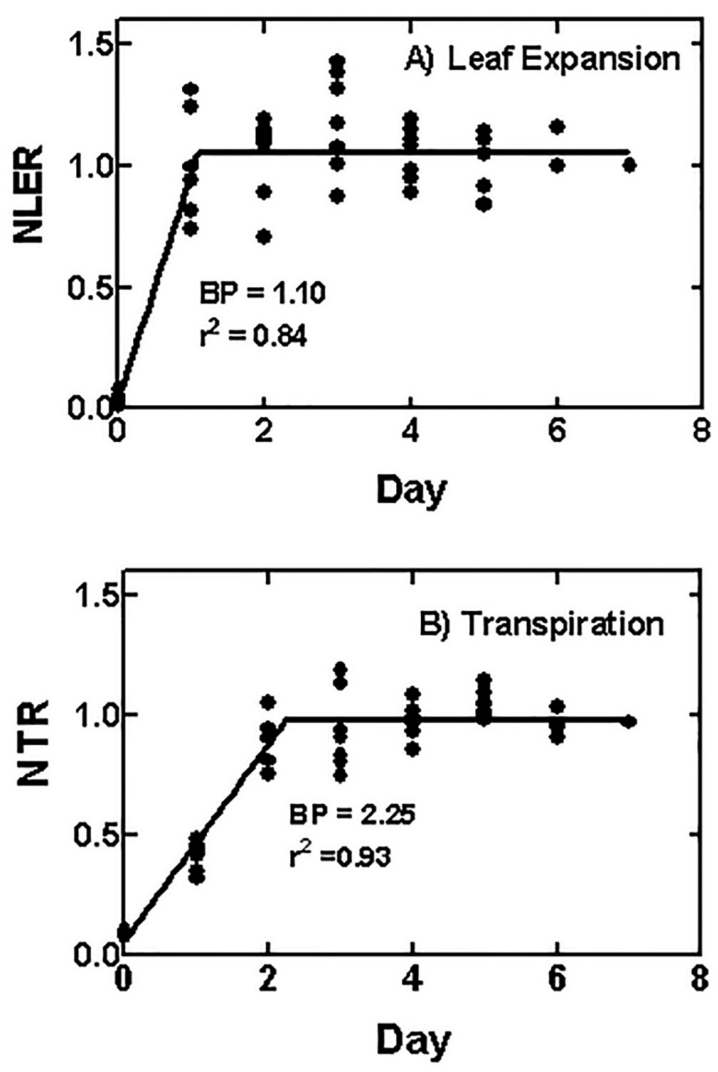

Fig. 4. Recovery for genotype IT89KD-288 of normalized leaf expansion ratio (NLER) and normalize transpiration ratio (NTR) following rewatering of severely stressed plants in Exp. 2.

leaf expansion response with transpiration response. This study also explored the ability of leaf expansion to recover on rewatering following drought treatment. Since the study included eight genotypes, the results of this study offer the first preliminary information about possible genotypic differences in leaf expansion.

For all genotypes tested, leaf-expansion response to drought fit the two-segment linear model with constant leaf expansion until soil water content decreased below a FTSW threshold, after which, leaf expansion decreased approximately linearly. The FTSW threshold for the decline in leaf expansion occurred earlier than the decline in NTR in all genotypes (Fig. 3). Additionally, the average extrapolated FTSW intercept at which the linear decrease in leaf expansion reached zero was higher than the FTSW intercept for the linear decrease in transpiration. Hence, the stopping point of leaf expansion also occurred earlier than transpiration. By both measures of sensitivity of leaf expansion to soil drying, leaf development in cowpea was more sensitive than transpiration to soil drying.

The results of these experiments indicated a large range exists in cowpea germplasm for values of the FTSW thresholds for decline in leaf expansion. Bambey 21 consistently had a decline in leaf expansion, $\sim 0.3$ FTSW. Mouride had a decline in leaf expansion at a higher FTSW of $\sim 0.4$ in the greenhouse and the second growth-chamber 
Table 3. Days for recovery of normalized transpiration ratio (NTR) and normalized leaf expansion ratio (NLER) following rewatering of plants in Exp. 2. Letters indicate significant differences based on 95\% confidence interval (Cl) within each experiment.

\begin{tabular}{|c|c|c|c|c|c|c|}
\hline Genotype & NTR threshold & $95 \% \mathrm{Cl}$ & $R^{2}$ & NLER threshold & $95 \% \mathrm{Cl}$ & $R^{2}$ \\
\hline & $d$ & & & $d$ & & \\
\hline Bambey21 & $2.17 a$ & $1.92-2.41$ & 0.91 & $1.05 a$ & 0.88 to 1.21 & 0.83 \\
\hline IT82E-18 & $1.99 a$ & $1.61-2.36$ & 0.92 & $\sim 0.69$ & (Very wide) & 0.70 \\
\hline IT84S-2049 & $2.33 a$ & $2.14-2.53$ & 0.95 & $1.11 a$ & $0.83-1.38$ & 0.66 \\
\hline IT89KD-288 & $2.25 a$ & $2.05-2.46$ & 0.93 & $1.10 \mathrm{a}$ & $0.94-1.26$ & 0.84 \\
\hline Mouride & $2.00 a$ & $1.62-2.38$ & 0.96 & $\sim 0.99$ & (Very wide) & 0.75 \\
\hline Suvita2 & $2.15 a$ & $1.98-2.31$ & 0.95 & $1.14 a$ & $0.82-1.47$ & 0.62 \\
\hline
\end{tabular}

experiment. Suvita 2 and IT89KD-288 also had high FTSW thresholds for leaf expansion among the genotypes tested. These genotypic differences might be valuable for genotype selection for varying environmental conditions. Genotypes with higher FTSW threshold for decline in leaf expansion can have the advantage in arid regions because they limit leaf-area development when water-deficit conditions develop and, hence, conserve water to sustain physiological activity during the period of drought. Whereas genotypes that have more tolerant leaf expansion response to soil drying, that is, lower FTSW thresholds, can be useful in wetter regions where it would be advantageous to have genotypes that can continue leaf development and take advantage of the available resources for optimum productivity. Since tracking leaf expansion in this experiment was nondestructive, it is possible to use this method to phenotype additional cowpea cultivars to guide selection in breeding programs.

A novel observation from this study was that on rewatering, full recovery of leaf expansion in these cowpea genotypes was seen in only $\sim 1 \mathrm{~d}$. This was true even though these cowpea plants were severely stressed to NTR $\leq 0.1$. Because of this rapidity of recovery, no difference in time to full recovery among genotypes was found. Recovery of leaf expansion was more rapid than transpiration rate recovery, but even transpiration rate recovered within an average of 2 to $3 \mathrm{~d}$. The fast recovery of both leaf expansion and transpiration on rewatering indicates that cowpea is well suited for sustaining increase in leaf area in dryland regions with intermittent drought.

Another noteworthy observation was the difference seen between the three experiments in the range of FTSW threshold. For both leaf expansion and transpiration, the FTSW thresholds occurred at a higher FTSW in the greenhouse experiment. For leaf expansion, the greenhouse experiment had the highest FTSW thresholds, with a range of 0.35 to 0.67 , and the growth chamber experiments had a range of 0.28 to 0.41 . Similarly, the FTSW thresholds for transpiration in the greenhouse occurred in the range of 0.31 to 0.58 , and in the growth chamber experiments, transpiration decline within 0.20 to 0.33 FTSW. The first growth-chamber experiment had the smallest FTSW threshold range of 0.28 to 0.37 for NLER and 0.22 to 0.25 for NTR. The smaller range for thresholds, especially for NTR, in the first growth-chamber experiment may be because the duration of the drought stress was too short to allow full expression of inhibited leaf expansion and transpiration earlier in the dry down.

The greenhouse and the second growth-chamber experiment both had, on average, longer periods of drought stress ( 13 and $11 \mathrm{~d}$, respectively) but the greenhouse had a range of higher FTSW thresholds than the second growth-chamber experiment. The differences seen in the FTSW thresholds between the experiments may be driven by differences in VPD. The greenhouse experiment had higher average VPD than the second growthchamber experiment, so the VPD environment may have resulted in the higher FTSW threshold than observed in the growth chamber experiments. Sensitivity of stomata to VPD has been documented in selected genotypes of soybean (Sadok and Sinclair, 2009), peanut (Arachis hypogaea L.; Shekoofa et al., 2015), maize (Zea mays L.; Messina et al., 2015), sorghum (Sorghum bicolor L.; Shekoofa et al., 2014). Further studies are needed to resolve the hypothesized sensitivity of the FTSW thresholds for decrease in leaf expansion and transpiration to VPD.

\section{Conflict of Interest Disclosure}

The authors declare no conflicts of interest.

\section{Acknowledgments}

The authors gratefully acknowledge the seed provided by Philip Roberts, Department of Nematology, University of California-Riverside, CA. Also, the authors acknowledge the useful discussions and assistance during this research provided by Avat Shekoofa, Mandeep Riar, Laleh Bagherzadi, Pablo RosasAnderson, Pepe Michelangeli, and Amber Beseli at North Carolina State University, Raleigh, NC.

\section{References}

Boyer, J.S. 1968. Relationship of water potential to growth of leaves. Plant Physiol. 43:1056-1062. doi:10.1104/pp.43.7.1056

Lecoeur, J., and T.R. Sinclair. 1996. Field pea transpiration and leaf growth in response to soil water deficits. Crop Sci. 36:331335. doi:10.2135/cropsci1996.0011183X003600020020x

Lim, T.K. 2012.Vigna unguiculata cv-gr. Unguiculata. In: T.K. Lim, Edible Medicinal And Non-Medicinal Plants: Vol. 2, 
Fruits. Springer Science+Business Media, London. p. 976-988. doi:10.1007/978-94-007-1764-0_104

Messina, C.D., T.R. Sinclair, G.L. Hammer, D. Curan, J. Thompson, Z. Oler, C. Gho, and M. Cooper. 2015. Limited-transpiration trait may increase maize drought tolerance in the US corn belt. Agron. J. 107:1978-1986. doi:10.2134/agronj15.0016

Sadok, W., and T.R. Sinclair. 2009. Genetic variability of transpiration response to vapor pressure deficit among soybean cultivars. Crop Sci. 49:955-960. doi:10.2135/cropsci2008.09.0560

Saravitz, C.H., R.J. Downs, and J.F. Thomas. 2009. Phytotron procedural manual for controlled-environment research in the Southeastern Plant Environment Laboratory. NC State University, NC Agric. Research Services, Raleigh. https://phytotron.ncsu.edu/procedural-manual/ (accessed 25 Apr. 2017).

Serraj, R., L.H. Allen, and T.R. Sinclair. 1999. Soybean leaf growth and gas exchange response to drought under carbon dioxide enrichment. Global Change Biol. 5:283-291. doi:10.1046/j.1365-2486.1999.00222.x

Shekoofa, A., M. Balota, and T.R. Sinclair. 2014. Limited-transpiration trait evaluated in growth chamber and field for sorghum genotypes. Environ. Exp. Bot. 99:175-176. doi:10.1016/j.envexpbot.2013.11.018
Shekoofa, Avat, P. Rosas-Anderson, T. R. Sinclair, M. Balota, and T. G. Islei. 2015. Measurement of limited-transpiration trait under high vapor pressure deficit for peanut in chambers and in field. Agron. J. 107:1019-1024. doi:10.2134/agronj14.0570

Sinclair, T.R., and M.M. Ludlow. 1986. Influence of soil water supply on the plant water balance of four tropical grain legumes. Aust. J. Plant Physiol. 3:329-341. doi:10.1071/PP9860329

Sinclair, T.R., A. Manandhar, N. Belko, M. Riar, V. Vadez, and P.A. Roberts. 2015. Variation among cowpea genotypes in sensitivity of transpiration rate and symbiotic nitrogen fixation to soil drying. Crop Sci. 55:2270-2275. doi:10.2135/cropsci2014.12.0816

Sinclair, T.R., R.C. Muchow, M.M. Ludlow, G.J. Leach, R.J. Lawn, and M.A. Foale. 1987. Field and model analysis of the effect of water deficits on carbon and nitrogen accumulation by soybean, cowpea and black gram. Field Crops Res. 17:121-140. doi:10.1016/0378-4290(87)90087-6

Soltani, A., F.R. Khooie, K. Ghassemi-Golezani, and M. Moghaddam. 2000. Thresholds for chickpea leaf expansion and transpiration response to soil water deficit. Field Crops Res. 68:205210. doi:10.1016/S0378-4290(00)00122-2 